\title{
Anterior Cusp of the Mitral Valve
}

National Cancer Institute

\section{Source}

National Cancer Institute. Anterior Cusp of the Mitral Valve. NCI Thesaurus. Code C127669.

The cusp of the mitral valve that is anchored to the aortic-mitral curtain. 